\section{P-103 RESTRUCTURING INCOME GENERATION IN THE MIDDLE OF A GLOBAL PANDEMIC}

Catherine Butterworth. St John's Hospice, Lancaster, Lancashire

10.1136/spcare-2021-Hospice. 120

Background Income generation plays a crucial part in funding charities and with only $1 / 3^{\text {rd }}$ funding received for our hospice, would it be sustainable to still have the current structure with the world in lockdown?

Aim To revaluate our current structure, implement changes to meet the changing face of fundraising, analysing data to influence and drive our income generation decisions going forwards whilst ensuring our systems and processes digital transformed the way we operate.

Methods May-June 2020: Evaluation of all current roles within Fundraising, Lottery, Grants and Legacies across two sites. August -September 2020: Full consultation with all staff members. October 2020 - staff receive confirmation of roles although still remain on furlough through pandemic; New supporter care team roles advertised and roles begin to work with the digital transformation plan.

Results Cost savings of $100 \mathrm{k}$ when income received in to the hospice was uncertain and our fundraising events had been diminished due to lockdown, rising COVID-19 cases and furloughed staff across many industries. Changed direction of resources into new Supporter Care team (SCT) whose aims was to ensure our data was fit for the future and could influence our decisions going forwards. Invested in a standalone role for legacy giving, an income stream that many hospices don't invest enough resource into (Remember A Charity, 2019. UK legacy fundraising market 2019; Remember A Charity, Legacy Foresight, the Institute of Legacy Management, and Smee \& Ford).

Conclusion Restructure is working well, new SCT fully trained on database allowing data to become more focused and relevant to our needs therefore subsequent mailings are donor specific allowing us to understand and map our donor journey. Fifteen months later the UK is still not back to full capacity after COVID-19 therefore the reduced fundraising team is currently adequate based on demands and income streams. A surge in wills during last 18 months has already seen an increase in supporter communication and a new legacy strategy is being implemented as a result of this consultation.

\section{P-104 A NOVEL APPROACH TO CARE-GIVING DURING A PANDEMIC: UPSKILLING NON-CLINICAL STAFF}

Sue Griffith, Alison Pegrum, Kaymarie Stabellini, Eva Lew, Alison Stevens. Farleigh Hospice, Chelmsford, UK

10.1136/spcare-2021-Hospice. 121

Background In early 2020 it became apparent that COVID-19 was going to have a major impact on hospice services. In anticipation of the pressures of giving end-of-life care to COVID-19 positive patients during a pandemic, the decision was made to increase clinical staff resource in the community. Aim The aim was to upskill non-clinical and allied health professional staff in a very short space of time, to prepare them to give end-of-life care, alongside experienced colleagues.

Method A two-day intensive training course, based on the core attributes identified in a concept analysis of being prepared for end-of-life care (Griffith, 2018), was devised and delivered to non-clinical staff who volunteered to help. Attendees were relocated into three community teams, and partnered with experienced carers and registered nurses to ensure that they were supported in practice. Supervision and guidance was given by colleagues and managers.

Results Following the teaching sessions, two staff members withdrew from the opportunity to take up a care role; six went ahead and joined the community teams. By the end of the first wave of COVID-19, three members of the fundraising team had returned to their usual roles, having enjoyed and benefitted from the experience, and gained greater insight into the service offered by our hospice. Two members of staff were successfully appointed to permanent roles in the community care team, and an allied professional remains in the role at the present time. The extra team members in the community helped to ensure that a comprehensive service was offered to increased numbers of people dying at home.

Conclusion Using a concept analysis to guide education planning, ensured a robust teaching programme, which successfully prepared non-clinical staff for a clinical role. This also confirms findings from a recent study of how prepared nurses feel a sense of 'fit' with hospice care (Griffith \& Gelling, 2021 [in press]).

\section{P-105 HOW DO YOU PLAN IN A PANDEMIC? ONE HOSPICE'S APPROACH TO RECOVERY AND TRANSFORMATION}

Kate Heaps, Aneta Saunders, Jon Devlin. Greenwich and Bexley Community Hospice, London, UK

\subsection{6/spcare-2021-Hospice. 122}

Background Having begun to plan for our next three-year strategy in 2019, the pandemic struck and we were faced with unprecedented uncertainty. Overnight we had to change our operations and our charitable income was slashed; we worked together to maintain services and due to hard work in fundraising and the government rescue packages available, our hospice remains in a reasonable financial position.

We didn't just survive, we have seen unprecedented change in our own organisation, across the health and care system and throughout society. Whilst this has been challenging, there are definite opportunities to be exploited to sustain and strengthen our charity and services. To simply return to life as it was pre-COVID-19 would be a missed opportunity and instead we're using the experience as a catalyst for positive change.

The Recovery and Transformation Programme (RTP), was developed to help facilitate our learning and set our future direction.

Aims The presentation will outline the seven main work streams we are focusing on to provide a foundation for our recovery. Work has been conducted during a time of significant residual uncertainty to progress towards achieving our vision, respond to opportunities and become more resilient to future threats; as well as helping us to shape and develop our longer-term strategy.

We will outline our renewed governance structure, established to support the work and to provide the oversight/assurance required as we move forward to the next stage of our development. 
Results The presentation will present improvements in: service transformation; volunteering; staff wellbeing and development; equality, diversity and inclusion; retail/commercial development; fundraising; and stakeholder engagement.

Conclusions Despite significant difficulties, COVID-19 has presented opportunities to be creative and energetic with our future thinking, expanding the 'art of the possible'. We have used the opportunity positively, bringing staff and board along with us and are a stronger, more confident hospice as a result.

\section{P-106 AN OVERVIEW OF THE DIGITAL HEALTH INTERVENTIONS ADAPTED AT ONE HOSPICE IN RESPONSE TO THE PANDEMIC}

Abi Ponnampalam. Farleigh Hospice, Chelmsford, UK

\subsection{6/spcare-2021-Hospice.123}

Background Palliative care services have responded rapidly and innovatively to the challenges of the COVID-19 pandemic (Dunleavy, Preston, Bajwah, et al., 2021; Etkind, Bone, Lovell, et al., 2020). Digital health interventions (DHI) have the potential to improve service provision (Finucane, O'Donnell, Lugton, et al., 2021; Bush, Perez, Baum, et al., 2018), with increasing evidence supporting the use of video consultations in palliative care as a safe and effective adjunct to face-to-face patient contact (Sutherland, Strickland, Wee, 2020).

Aim To evaluate the extent to which two digital health interventions were adapted by one hospice in response to the COVID-19 pandemic.

Method An electronic health record system was already in use (SystmOne) at the hospice and these new digital health interventions were incorporated in response to the pandemic:

- Video consultations.

- 'Authority to Administer' (ATA) electronic charts on SystmOne, authorising administration of injectable medications by community nurses for people at end-of-life being cared for at home. These were in addition to paper community drug charts, usually completed by GPs, community or hospice prescribers.

Results

- Video consultations: From none (pre-pandemic) to a monthly average of 68 in early 2020, nearly doubling to an average of 132 in early 2021.

- ATAs increased from a monthly average of five (mid 2020) to 27 (first quarter, 2021).

- $35 \%$ of ATAs (49 out of 144 in a 42 week period) were completed at weekends or late evening, with likely patient benefit as delays awaiting completion by urgent care prescribers were potentially avoided.

Conclusion Digital health interventions are firmly embedded in the day to day provision of palliative care services. As well as using NHS approved software such as accuRx for secure video consultations, staff have also innovated in using this technology to communicate more effectively with patients, such as sending clinic letters, symptom assessment questionnaires, patient information leaflets and text summaries of medication changes directly to patient devices. There is huge scope to incorporate digital health interventions further within palliative care to meet the changing needs of local communities.

\section{P-107 EARLIER SPECIALIST PALLIATIVE CARE INPUT ON THE ACUTE ONCOLOGY ASSESSMENT UNIT: IS IT BENEFICIAL?}

Peter Westwood, Anna Schuberth, Suzie Gillon, Adam Hurlow. Leeds Teaching Hospitals NHS Trust, Leeds, UK

\subsection{6/spcare-2021-Hospice. 124}

Background Emerging evidence suggests early palliative care (PC) is beneficial in the care of patients with cancer (Berman, Mola, Elliott, et al., 2018; Mola, Campbell, Berman, et al., 2018; Temel, Greer J, et al., 2010). Clinicians' views also require consideration as they aim to support and optimise care for these patients (Popescu, Schafer, Califano, et al., 2014).

Aims To evaluate our model of earlier PC on the Oncology Assessment Unit (OAU), assessing the effect on patients and clinicians.

Methods Two PC doctors attended the OAU at a tertiary cancer centre, for 45 sessions. PC intervention consisted of faceto-face review or advice. The number of, and reasons for referrals were recorded. Patient and staff questionnaires provided feedback. Staff responses were independently analysed to identify themes.

Results

- 41 referrals: 32 face-to-face reviews; 9 advice only.

- 16/41 not previously known to PC services.

- Seven patient and 10 staff questionnaires returned.

All patients gave positive feedback and would recommend PC to family/friends. Thematic analysis of staff responses identified three themes:

1. Access to/engagement with PC services: Removing barriers to PC services, providing good links to Community PC Services. 'Discussion with the PC doctor seemed to de-mystify/take away some of the fear associated with PC referral'

2. Quality of care: Good patient care, efficiency/patient flow, expertise in symptom control. 'It has improved patient care on the two occasions I referred'

3. Improved outcomes

4. Preferred place of care, advance care planning, education/ teaching. 'This was highly beneficial to the patients as they wanted to be at home and we were able to carry out their wish safely'.

Conclusion Access to palliative care has been widened, quality of care and patient outcomes improved. Patients and staff were positive about early palliative care in this setting. Consideration is required to ascertain if this model of care is (a) the optimal use of resources and (b) transferrable to other settings.

\section{P-108 A LONG TERM VENTILATION (LTV) SERVICE- DEVELOPMENT OF SENIOR CARE ASSISTANTS}

Jenna Ridout, Rachel Van Den Brink-budgen, Harriet Warriner, Linda Maynard, Tina Howlett. East Anglia's Children's Hospices, Cambridge, Cambridgeshire

\subsection{6/spcare-2021-Hospice. 125}

Background The number of children and young people with Long Term Ventilation (LTV) needs accessing hospice services continues to increase. This paper outlines the provision of a 